\title{
Factors Influencing Knowledge and Persuasion of Financial Regulators in the XBRL Adoption Process: The Technological Perspective
}

\author{
Azleen Ilias ${ }^{1}$, Erlane K Ghani ${ }^{2} \&$ Zubir Azhar $^{3}$ \\ ${ }^{1}$ College of Business and Administration, Universiti Tenaga Nasional, Malaysia \\ ${ }^{2}$ Faculty of Accountancy, Universiti Teknologi MARA, Malaysia \\ ${ }^{3}$ School of Management, Universiti Sains Malaysia, Malaysia \\ Correspondence: Erlane K Ghani, Faculty of Accountancy, Universiti Teknologi MARA, Malaysia.
}

Received: April 20, 2019

doi:10.5430/ijfr.v10n3p170
Accepted: May 7, 2019

Online Published: May 19, 2019

URL: https://doi.org/10.5430/ijfr.v10n3p170

\begin{abstract}
This study examined the factors influencing XBRL adoption process among the Malaysian regulators in the financial reporting environment. Specifically, this study aims to examine the drivers and challenges in the knowledge and persuasion phase faced by the Malasyain regulators in their adoption process of XBRL. This study relied on two frameworks namely, the adoption process framework with specific focus on knowledge and persuasion, and the TOE framework focusing on technological context. Using a qualitative approach, this study found that within the technological context, relative advantage and trialability were the drivers in the knowledge and persuasion phase. This study also found that the regulators were aware of XBRL and had made efforts to understand the XBRL taxonomy. However, the regulators were needed to develop the internal capability of their organisations since different regulators have shown different factors during the knowledge and acquisition phase that is necessary for XBRL adoption. The findings in this study serve as guidelines to other regulators in Malaysia and other countries that have plans to adopt XBRL.
\end{abstract}

Keywords: adoption process, XBRL, drivers, challenges, regulators, Malaysia

\section{Introduction}

The development of XBRL has evolved for more than a decade (Ghani, Laswad \& Tooley, 2009, 2011), beginning from 2000 until 2018, following worldwide changes that had affected the financial reporting landscape. With the huge amount of data at hand, stakeholders, such as the regulators, government agencies, companies and end-users, need to exchange and share valuable data. XBRL International (2018) has identified ten regulators from ten countries that have produced open data using XBRL. The regulators are Companies House (CH) (UK), Securities and Exchange Commission (SEC) (USA), Danish Business Authority (Denmark), German Business Registry (Germany), Peruvian Securities Regulator (Peru), Financial Services Agency or FSA (Japan), Spanish Business Registrar (Spain), Accounting and Corporate Regulatory Authority or ACRA (Singapore), Repository of Korea's Corporate Filings (Korea) and the La Superintendencia de Valores y Seguros (Chilean Securities Regulator). In Malaysia, XBRL has yet to be fully adopted due to none adoption by public listed companies probably. The regulators are also looking into adopting XBRL, which is in line with the international requirements. XBRL has been around for over a decade and many parts of the world have moved towards it. This is because the stakeholders and the information supply chain need to obtain data for analysis and decision making (Cohn, 2017).

Studies have also examined the drivers and challenges of adopting XBRL (Doolin \& Troshani, 2007; Mousa, 2010; David, 2016). However, most of these studies were conducted in developed countries namely New Zealand (David, 2016) and Australia (Doolin \& Troshani, 2007), resulting in a lack of similar study in developing countries. As of to date, the Philippines Securities Commission has started evaluating the feasibility of using XBRL for reporting purposes (XBRL International, 2017). Similarly, the National Bank of Cambodia has indicated its interest to start implementing XBRL, but they are still working on initiatives prior to adopting XBRL (XBRL International, 2017). Thus, arguably, there is a need for a study to understand the XBRL adoption process in Malaysia, particularly on the factors influencing the adoption process.

This study aims to examine the factors influencing the adoption process of XBRL among four regulators in the 
financial reporting environment from the technological perspective. The findings of this study serve as a guideline for regulators and government agencies as well as contribute to the corpus of existing academic knowledge and literature. The next section, Section 2 presents the literature review related to this study. This is followed by Section 3 that explains the research design of this study. Section 4 provides the findings of this study. The last section, Section 5 summarises and concludes this study.

\section{Literature Review}

Most of the literature on XBRL adoption had examined XBRL adoption using three main contexts which can be used to understand the factors in XBRL adoption (DePietra, Wiarda \& Fleischer, 1990; Troshani \& Rao, 2007; Mousa, 2010; Cordery, Fowler \& Mustafa, 2011; David, 2016). Each of the contexts comprises several factors that vary between studies. The three main contexts are technological context, organisational context and environmental context. This study focuses on technological context. Technological context refers to the description of both internal and external technologies, including current internal practices and equipment as well as the available technologies external to a company and how the technology's features can influence adoption process (DePietro et al., 1990).

According to Rogers (2003), there are three phases in the adoption process, from the knowledge gathering phase until the confirmation to adopt an innovation phase. DePietro et al. (1990) also mentioned that the adoption process often involves awareness of the problem, deployment of the innovation as well as the adoption of commitment, implementation and routinisation. In addition, DePietro et al. (1990) had indicated that Rogers' (1983) adoption process model is appropriate for investigating XBRL adoption process, which is divided into three phases: gathering knowledge and persuasion, decision making as well as implementation and confirmation. This study focuses on the first phase which is knowledge and persuasion.

Rogers (2003) stated that when the individual is first exposed to an innovation that he is not familiar with due to lack of information about the innovation. During this phase, the individual is not yet inspired to explore for more information about the innovation. Then, there is the persuasion process. Rogers (2003) stated that the individual is interested in the innovation and actively seeks related information/details. In addition, DePietro et al. (1990) indicated that there is a need to gain knowledge or understanding necessary to determine recognised and specific needs. DePietro et al. (1990) examined the availability of technology and contemporary technology that fits a company's current technology platform as two factors affecting decision to adopt technology. Rogers (2003) suggested other factors such as relative advantage, compatibility, complexity, trialability and observability. These factors can either become a driver or a challenge to the XBRL adoption process.

Rogers (2003, p.229) defined relative advantage as "the degree to which an innovation is perceived as being better than the idea it supersedes. The degree of relative advantage is often expressed as economic profitability, conveying social prestige or other ways". Relative advantage is a form of drive that encourages technology adoption (Iacovou, Benbasat \& Dexter, 1995). The literature on information systems shows that the more an organisation presumes the probable advantage of a technology, the more likely the organisation would initiate adoption (Folorunso, Vincent, Adekoya \& Ogunde, 2010; Al-Jabri \& Sohail, 2012).

Relative advantage has become a driving factor in XBRL adoption (Mousa, 2010; Henderson, Sheetz \& Trinkle, 2012). Numerous studies have shown that organisations that adopt XBRL have improved data accessibility (Pinsker $\& \mathrm{Li}, 2008$ ), reduced time and costs when generating reports (Taylor \& Dzuranin, 2010) and exercised less effort in converting reports from different formats (Taylor \& Dzuranin, 2010). Moreover, XBRL adoption offers a competitive advantage to XBRL adopters (Pinsker \& Li, 2008). Troshani and Doolin (2005) suggested that XBRL is perceived as a form of competitive advantage in relation to increased quality and efficiency. Similarly, Cordery et al. (2011) identified a relative advantage to influence the decision of companies to adopt XBRL in New Zealand. However, David (2016) found relative advantage is not a driving force to XBRL adoption in New Zealand. Nevertheless, some studies have shown otherwise. As an example is a study by Steenkamp and Nel (2012) that found that companies in South Africa felt no benefits in adopting XBRL. This is similar to Rosa and Caserio (2013), who found that XBRL cannot drive auditors to adopt XBRL since they are bound by regulatory requirements.

The next factor is compatibility. Rogers (2003, p.240) defined compatibility as, "the degree to which an innovation is perceived as consistent with the existing values, past experiences and needs of potential adopters. An idea that is more compatible is less uncertain to the potential adopter and fits more closely to the individual's situation". DePietro et al., (1990) defined compatibility as how available technology fits with current technology. Studies have shown that compatibility is one of the factors that influences internet adoption (Zhu, Kraemer \& Xu, 2006), mobile banking (Al-Jabri \& Sohail, 2012), e-commerce (Hussin \& Noor, 2005) and 3G services (Ong, Poong \& Ng, 2008). However, Hussin and Noor (2005) found that compatibility does not influence e-commerce in Small and Medium 
Enterprises since they do not feel that the role of e-commerce in the current business process is important.

Within the XBRL literature, Tie (2005) noted that XBRL's compatibility with a software is important and needs to be understood by software vendors. Henderson et al. (2012) found compatibility to significantly influence XBRL adoption for internal purposes more than for inter-organisational purposes. In non-adoption of XBRL, Cordery et al. (2011) found that compatibility influences the decision not to adopt XBRL, whilst Steenkamp and Nel (2012) found compatibility in the old system needed to adopt XBRL.

Another factor is complexity which is known as "the degree to which an innovation is perceived as relatively difficult to understand and use" (Rogers, 2003, p. 257). Rogers (2003) suggested that complexity is a significant barrier to adoption and is negatively related to the rate of innovating adoptions. Studies on technology adoption have faced similar difficulties, such as complexity of the system as well as infrastructure. Complexity of the system and infrastructure are important factors in the technology context, which are considered barriers to the adoption of various technologies, such as the adoption of e-Commerce (Rodgers, Yen \& Chou, 2002; Valmohammadi \& Dashti, 2016), e-Government (Kaur \& Noor Rashid, 2008) and e-Signature (Srivasta, 2011).

According to Doolin and Troshani (2007), XBRL involves the inter-organisational element because it connects an organisation with other stakeholders such as vendors, suppliers, customers, bankers, analyst, regulators, share exchange, auditors and others involved in business operations. Hence, with the involvement of various parties during the adoption process, the process becomes more complex, thus, sufficient and capable expertise is needed to handle emerging issues. Various researchers have agreed that the issue of complexity is one of the challenges faced when adopting XBRL (Troshani \& Doolin, 2005; Troshani \& Rao, 2007) as complexity of XBRL taxonomy and specifications could diminish XBRL usefulness (Bartley, Chen \& Taylor, 2011). In the case of non-adoption, David (2016) found that complexity influences the organisation to abandon XBRL. Meanwhile, Henderson et al. (2012) stated that focus on factors that influence adoption in inter-organisational and internal organisational circumstances found that complexity significantly influenced XBRL adoption for internal purposes more than inter-organisational purposes.

Next is trialability. Rogers (2003, p.258) defined trialability as, "the degree to which an innovation may be experimented on a limited basis". He stated that trialability has a positive effect on technology adoption. Dedrick and West (2003) also agreed that this element had an advantage on technology adoption. Trialability is one of the important factors that influences the attitude to use social networking (Folorunso et al., 2010). Doolin and Troshani (2007) suggested that trialability is at a pilot stage and needs to reduce the uncertainties associated with XBRL adoption so that organisations are confident with XBRL. Cordery et al. (2011) mentioned that trialability is related to relative advantage because it analyses the advantages prior to XBRL adoption. According to Doolin and Troshani (2007), knowledge of unproven benefits prior to adoption would probably discourage continuous trials and investment in XBRL adoption. While in the case of non-adoption, Cordery et al. (2011) and David (2016) found that trialability influences the decision to adopt or not to adopt XBRL.

The last factor is observability is defined as "the degree to which effects of technology are visible to others. Some ideas are easily observed and communicated to other people, whereas other technologies are difficult to observe or describe to others" (Rogers, 2003, p. 258). Moore and Benbasat (1991) had identified observability based on two factors, namely demonstrability and visibility. Slyke, Belanger and Comunale (2004) also tested demonstrability and visibility related to the intention to purchase goods through the web. Hussin and Noor (2005) found that observability influences future adopters to adopt e-Commerce. Folorunso et al. (2010) suggested that observability does not only focus on observing people using technology, but also how technology is related to perception, evaluation and third-party influence. According to Al-Jabri and Sohail (2012), observability is the ability to observe benefits accrued from adopting mobile banking. Doolin and Troshani (2007) also mentioned that observability influences XBRL adoption in Australia since organisations need to observe and experience the benefits of XBRL although the capability to observe XBRL products and readily available XBRL applications depends on the suitability of XBRL capabilities with organisational needs. Pinsker and Li (2008) stated that in the US, there is uncertainty on the benefits of unproven technology that influences the decision to adopt. It would be interesting to examine whether the findings shown in the previous studies would also be reflected in this current study.

\section{Research Design}

\subsection{The Respondents}

This study chose the regulators in the financial reporting environment to be the respondents in this study. The regulators in the financial reporting environment play a key role in expediting XBRL adoption (Abdullah, Khadaroo 
and Shaikh, 2009; Cordery et al., 2011; Dunne et al., 2013). Studies have shown that the regulators in many countries have keen interest in XBRL (Weber, 2003). The selection of respondents was based on purposeful sampling because the researcher intended to select individuals in order to learn and understand the central phenomena of XBRL adoption among Malaysian regulators. Four regulators were chosen. These four regulators in this study are known as Regulator 1, Regulator 2, Regulator 3 and Regulator 4 in order to remain anonymous.

\subsection{The Case Study}

This study used the case study approach in examining XBRL adoption process among the four regulators in the financial reporting environment. The use of this approach is consistent with Rosa and Caserio (2013); Mousa (2016) and David (2016). As in XBRL research, the researchers examined XBRL-related phenomena in its natural setting and gain an in-depth understanding of the nature and complexities of the adoption process scenario (Mousa, 2010; David, 2016) which can only be obtained in relation to a particular country which is Malaysia (Ryan et al. 2002; Chidoko and Mashavira, 2014; Abiola and Olausi, 2014; Krishnan and Kumaran, 2015; Abedin and Dawan, 2016).

\subsection{Data Collection}

This study relied on interview and content analysis. This study employed face-to-face interviews, whereby data collection was done directly with the respondents in their organisation. To seek permission, official letter was sent to each respondent before the data collection, followed by a phone call. The interview used semi-structured and open-ended questions in order to gather data. The questions were prepared or adapted when necessary, and change with any doubt, which can adapt based on the regulator's adoption phase. This study also performed content analysis whereby the regulators' documents were reviewed pertaining to the regulators' current development, taxonomy and filling development for 2014, XBRL taxonomy framework and XBRL development for the regulators, which involved reporting, taxonomy and filling. In addition, this study also reviewed the strategic plan for XBRL, the main XBRL website and the International Accounting websites.

\section{Findings and Diregulator Disussion}

Rogers (2003) had identified the first phase of the adoption process as the knowledge and persuasion phase. In this phase, the regulators start to gather information on the advantages of adopting XBRL. The adoption process during this phase involves providing awareness and understanding how XBRL can be implemented at the inter-organisational and intra-organisational levels. This ensures that the regulators understand the benefits XBRL adoption and how this technology can be used in a pilot study prior to deciding on whether to adopt or reject. This study had identified two factors which were relative advantage and trialability, under the technology context that influences regulators to adopt XBRL.

\subsection{Relative Advantage}

Throughout this phase, the regulators had to identify the relative advantage of XBRL adoption, which varied among regulators. In this example, Regulator 1 had considered the advantage of data quality through a wide array of statistical information when using XBRL.

"The transformation to have wide statistical information will provide benefits to the Regulator 1 since they are concerned about the quality of data. The decision to transform to the technology will ensure the efficient data management, the easy accessibility to credible and relevant data, able to eliminate the data duplication and ease for IT maintenance and support" (Regulator's presentation, Regulator 1, 2013).

Regulator 1 developed a system that comes together with both offline and online submissions incorporated into the XBRL taxonomy, which was adapted according to the banking institution environment. The existing environment involving the statistical and analytical systems was changed to the Enterprise-Wide Information System. Thus, integrating the system and XBRL based on the environment could help achieve the objectives of XBRL adoption. This was stated in its internal document, as follows:

"This Enterprise-Wide System information that is being developed will resolve the past system boundaries associated with data consistency, accessibility and usability. Additionally, this new environment will unite all financial and economic statistical data submitted to a centralized, standardized and unified platform" (Internal Document, Regulator 1, August 2010).

Another regulator, Regulator 3, noticed the advantage of data quality for the purpose of market utilisation related to information asymmetry. This issue was discussed in their masterplan:

"The quality of markets is also judged by how information asymmetry which a situation where one party has more information than the other party is addressed. It is not only important that there is adequate disclosure of 
information, but that the information is also easily available and accessible to all investors" (Strategic Masterplan, Regulator 3, April 2011).

The discussion on Regulator 3's masterplan stipulated that this is a relative advantage that addresses information asymmetry by discarding the weaknesses of past practices. Thus, Regulator 3 was concerned about this challenge, as mentioned in its strategic masterplan:

"Addressing information asymmetry challenges by strengthening the infrastructure for cost-effective and efficient data capture, information gathering, analysis, disclosure and corporate communication" (Strategic Masterplan, Regulator 3, April 2011).

At the knowledge and persuasion phase, Regulator 3 developed a strategy for adopting XBRL based on the objective of realising XBRL's relative advantage. Regulator 3 stated in the masterplan that the strategies aim to produce a highly electronic Malaysian capital market environment and there is a need to have a clear and holistic roadmap for such a development:

"Intent to address the information asymmetry challenges true the strengthening the infrastructure in order to ensure the cost-effective and efficient data capture, information gathering, analysis, disclosure and corporate communication. Then the data framework for taxonomy is established and data management policies for the purpose to ensure data consistency and integrity as well as aggregation and automation of data flows. Incorporate with the initiative, there is establishment of data reporting requirement to facilitate the aggregation of enterprise wide and market data on a real-time basis" (Strategic Masterplan, Regulator 3, April 2011).

Regulator 2 also believed that the relative advantage of XBRL adoption was in line with worldwide adoption plans:

"Substantial and prevailing benefits that would be gained by regulators and filers/companies through implementation of XBRL such as reduced time and cost of gathering financial or non-financial information, exchanging or sharing company information amongst regulators and capable of translating information into various languages" (Regulator's presentation, Regulator 2, 2012).

The Malaysian regulators had made efforts to learn and actively identify the relative advantages of XBRL adoption. Based on the feedback by Regulator 2, this study found that Malaysian regulators realised the need to adopt XBRL.

"Regulator 2 and other regulatory bodies see the numerous needs and benefits of XBRL to the country such as bringing in more foreign investors, provide deep insights into the financial health of businesses, provide critical business data to the government for policy decisions and so on".

In order to gain the advantage of a new ecosystem that incorporates XBRL, regulators should focus on the delivery and accuracy of information, analytical capabilities and the relationship with external stakeholders. Regulator 2 aimed to adopt XBRL and strategized the adoption process to gain the relative advantages of XBRL. Commencement of the XBRL project by Regulator 2 was aimed:

"[...] to enhance the delivery and accuracy of financial statements and annual return information and to achieve a standardised and consistent mode of reporting with enhanced analytical capabilities and to promote ease of information /data exchange flow with external stakeholders" (XBRL Taxonomy Document, Regulator 2, 2017).

In addition, Regulator 4 clarified that XBRL submission was based on a specific reason, such as to gather useful data for tax auditing purposes. In addition, the preparation and submission of tax statements in XBRL reduces human error and provides high quality data. Regulator 4 noted that:

"The reason for the submission to XBRL is that XBRL is capable of producing beautiful data, so we do not have to provide people for data entry, when you manually submit, have data entry, we need to key in the data to get into our system, sometimes if there is a human error in the wrong key. If you enter your (company) own, then you (the company) will confirm that the data is correct".

Regulator 4 noted that the issue was voluntary and mandatory adoption of XBRL. Thus, if it was voluntary, the implementation involves submission, either manually and using XBRL. Voluntary submission involves manual submission by filers. In addition, XBRL submission affects the rate of compliance in Malaysia. This is because the XBRL team that had studied XBRL submission based on cases from the United Kingdom pertaining to how XBRL provides advantage to filers. Regulator 4 further mentioned that:

"But if they (filers) submit manually, they will take it easy, but if in submission on the system for XBRL, it will be correct. If viewed from other countries, their data show accuracy as the rate of compliance is higher. In Malaysia compliance rate is almost to $40 \%$, compared to UK or German, compliance rate is $90 \%$. The reason for their 
information like this (XBRL), they cannot run. Like I go to Dublin, all their systems are connected with each other, bank systems are also in contact with their revenue agencies".

Regulator 4 foresaw the relative advantage of XBRL for the purpose of tax audit analysis. This regulator facilitated from a tax perspective as XBRL can provide comprehensive financial statements that could be used for tax analysis. Hence, XBRL can be used to solve current practices in tax analysis. Regulator 4 noted that:

"When the project is carried out, the benefits will be seen for tax payers and Regulator 4, whereby the preparation of financial statements will be comprehensive. Hence, it will reduce time and costs when preparing financial statements, in which Regulator 4 would not have to request any supporting documents for tax analysis purposes".

Prior to the concern on tax analysis usage, ideas for understanding the XBRL concept and the relative advantage of adopting XBRL, Regulator 4 had come across ideas related to the tax form used for tax audit analysis since these data are important to Regulator 4 users. The XBRL team had emphasised that one government agency (PEMUDAH) had commented about the tax form in which the form needs to be simplified. However, a simplified tax form would be appropriate for collecting a company's financial data for tax audit analysis, as mentioned by Regulator 4:

"Actually, we are looking into this project because PEMUDAH have commented about the form and we need to simplify the form due to the thickness of the form. We need to simplify the form into at least two pages for example like the e-filing. We need to simplify the form that being used for company to submit their data and this particular company's tax form has yet to be simplified. Thus, the way to simplify the form is by thinking to adopt the XBRL".

At this phase, Regulator 4 was interested in understanding more about XBRL and whether this technology provides advantages for both the regulator and tax payers. This would enable taxpayers to prepare a more comprehensive financial statement to ensure a more effective tax audit analysis. This standardised submission for tax returns would provide advantage for filers since tax return submissions in XBRL reduces filing and submission costs. Regulator 4 explained that:

"For tax payers, less of time and money because hopefully they will prepare everything in one time but we need to provide them with template form and secondly because the form can be convert using customise programme and taxonomy. For regulator's operation, our staff do not have to request any supporting documents anymore for audit purpose because we have need to focus on extracting the data using whatever tools to choose for high risk tax payers, we can analyse the data more detailed without requesting any documents, because we have everything now. Furthermore, the selection for risk case will be more accurate with less time and cost. Thus, by having XBRL, we can simplify the tax form, do not have to print and can do it online. We can see the expected benefits when extracted from website and can send via online for our operation”.

"For the tax audit case, the filers will keep the information that related to tax computation and documents, so we (Regulator 4) can review and check for example for incentive application. That is for the purpose of to conduct the tax audit in identifying high risk filers. So, with this (XBRL), the cost of filing for filers will be reduce and our (Regulator 4) filers do not have to submit by hand any documents".

In addition, Regulator 4 also clarified that XBRL submission has a specific purpose, which is providing useful data for tax audits purposes. In addition, XBRL preparation and submission of data might also reduce human error and provide high-quality data. Regulator 4 had mentioned the reasons for adopting XBRL, as follows:

"The reason for the submission to XBRL is that XBRL is capable of producing beautiful data, so we (Regulator 4) do not have to provide people for data entry, when you manually submit, have data entry, we (Regulator 4) need to key in the data to get into our system, sometimes if there is a human error in the wrong key. If you enter your (company) own, then you (the company) will confirm that the data is correct".

$\mathrm{XBRL}$ is not actually a new tool in the global arena. Since its existence more than 15 years ago, regulators have been pressured to adopt XBRL because many countries have done so. Despite not being new, this study found that regulators were struggling to develop XBRL and it took them a long time to develop the technology, as noted by Regulator 2:

"Regulator 2 and other regulators see the benefits and importance of implementing XBRL in Malaysia although this format is still new in Malaysia and there will be challenges for its development".

In sum, through the knowledge and persuasion phase, regulators realised the relative advantage of adopting XBRL. They also realised that XBRL could improve and overcome the challenges posed by past financial reporting practices that were related to producing financial data. Subsequently, XBRL adoption can overcome the shortcomings of past practices related to the submission method for any related report required by regulators. 


\subsection{Trialability}

During the knowledge and persuasion phase, trialability is accomplished so that XBRL works according to regulators' objectives. Trialability reduces uncertainty and improves readiness to adopt XBRL. This study found that regulators should aRegulator 3ertain that XBRL taxonomy and the submission platform are complete before the adoption. Upon hearing the relative advantage of XBRL, Regulator 3 attempted to learn more about XBRL, as mentioned by Regulator 3:

"I think what we are looking in the earliest days is whether the technology is ready as what people create, now we heard people saying a lot of good things, it may not be so good to implement it, there are XBRL stage that have some benefits, that is why we started a pilot project. We wanted to know how XBRL benefits the market".

Furthermore, Regulator 3 had taken the initiative to learn about XBRL prior to deciding to adopt XBRL. Officer Regulator 31 from the XBRL team stated that Regulator 3 had learned how XBRL could be applied in the Malaysian capital market. In addition, Officer Regulator 3 also stated that XBRL cannot be outright adopted by regulators if the technology is ill-prepared for submission. Regulator 3 adopted XBRL by first carrying out a pilot project to attract filers once the technology was ready. Thus, if the technology is unable to attract filers, the regulator should meet the filers personally and accommodate the cost.

"We are looking how we apply XBRL to Malaysian capital market, we want to know those how benefit XBRL to the market. At least we try to get attraction as soon as possible, otherwise the technology is sitting there, every year it will incurring the cost before used it and become obsolete".

For Regulator 4, their readiness relates to the development of XBRL taxonomy and submission platform. The two development processes consisting of XBRL taxonomy and submission platform were consistent with Regulator 4's objectives. The XBRL taxonomy and systems were based on the designation of Regulator 4. However, technological readiness passed some challenges during the test to ensure XBRL taxonomy and the system are in line with the regulator's requirements. Therefore, Regulator 4's readiness had changed according to XBRL, leading to a change in the implementation period. This was explained by Regulator 4:

"Regulator 4 has a target that needs to be followed and it is possible that we (Regulator 4) can be done as we (Regulator 4) are ready to be able to do the pilot implementation but implementation it may be in year 2017 because we (Regulator 4) must take time as well".

\subsection{Discussion on the Drivers and Challenges on the Knowledge and Persuasion Phase of XBRL Adoption Process}

In the knowledge and persuasion phase, the regulators are in the midst of obtaining information related to XBRL adoption. According to Rogers (2003), there is a lack of information on XBRL adoption in this phase and the need to identify more information on related innovations. Since XBRL has been developing over the past 20 years and adopted in the international context, Malaysian regulators have no issue on XBRL awareness. The four regulators became aware of XBRL and made efforts to understand XBRL taxonomy. However, knowledge and skills related to XBRL taxonomy development and submission platform is considered important, whereby Malaysian regulators would need to develop the internal capability of their organisations. Different regulators have shown different factors discovered during this stage that is necessary to start XBRL development (Ekpete and Iwedi, 2017; Nazal, 2017; Adusei, 2018; Syadullah, 2018; Elkhayat and ElBannan, 2018; Ghosh, et.al.2018; Cheng, et.al. 2018; Liu and Yin, 2018).

According to Rogers (1983), the earlier stage of searching for any knowledge regarding XBRL had coerced the adopter to reveal any knowledge on XBRL and how XBRL works in the current situation. According to the four regulators, they became aware of XBRL once they realised the challenges of current financial reporting practices related to the submission of reports by filers. This had encouraged them to learn the need to adopt XBRL, both, for intra and inter-organisational purposes.

Due to the challenges in past practices, regulators have identified and understood that XBRL provides relative advantage to their submission process, whether within the organisation or with their filers. In this phase, they realise that XBRL provides benefits based on each regulator's needs. Usually the regulators are concerned about producing high-quality data from the adoption of XBRL, whereby they need accurate and reliable data to be used for any decision making process within the organisation. The relative advantage could drive regulators to improve past practices. Thus, relative advantage is a factor that persuades regulators to further understand XBRL implementation. Hence, by understanding XBRL, Regulator 1 had realised the advantages offered by XBRL adoption. They believed that the data produced could consolidate reliable financial and economic statistical data and meet their expectations for data demand (Omodero and Ogbonnaya, 2018; Hallunovi and Berdo, 2018). 
Similarly, Regulator 3 also realised that XBRL could provide benefits for Regulator 3 by producing high-quality data and reduce information asymmetry. Regulator 2 was aware of the advantages that come along with XBRL adoption in their organisation. They agreed that XBRL benefits both regulators and filers, who produce financial and non-financial information that can be shared and exchanged easily between regulators and companies. Regulator 4 saw the benefits available by implementing XBRL, particularly comprehensive financial statements for tax audit operations. XBRL has been implemented by various regulators and government agencies in Asia, Europe and America. At the early phase of gathering information, each regulator involved in XBRL development has to identify and understand the XBRL concept. The regulators tried to understand how XBRL benefits the preparation of reports and how it suits their current environment. They started with the initiative to learn more about XBRL with each regulator understanding the benefits of XBRL implementation.

At the gathering of knowledge and persuasion phase, challenges posed by past practices and relative advantage have driven regulators to adopt XBRL. This study found that regulators had the interest and initiative to adopt XBRL in order to reap its benefits. Regulators saw that XBRL could improve their current practice of preparing financial statements and collecting data from filers for the purpose of data analysis. In UK, Mousa (2010) found that relative advantage influenced the XBRL adoption process during the knowledge gathering phase. While in the US, Henderson et al., (2012) found that relative advantage strongly influenced the internal decision to adopt XBRL. As opposed to the Regulator 3ene in New Zealand, there was no relative advantage in the adoption of XBRL (Cordery et al., 2011) since organisations disagreed that XBRL could reduce compliance cost. Doolin and Troshani (2007) and Steenkamp and Nel (2012) found that there was a lack of relative advantage when adopting XBRL. David (2016) suggested that the government and private organisations did not seek to adopt XBRL because the costs were perceived to exceed the benefits. Table 1 presents the challenges of past practices faced by the Malaysian regulators.

Table 1. Challenges of past practices

\begin{tabular}{ll}
\hline Regulator 1 & Timeliness of data, reporting burden and cost of doing business, increasing demand of data from users \\
\hline Regulator 3 & Information asymmetry \\
\hline Regulator 2 & Integration of their six databases in their submission environments \\
\hline Regulator 4 & Difficulty when we need to request supporting documents for audit purpose \\
\hline
\end{tabular}

During the knowledge gathering and persuasion phase, trialability was another factor that could influence XBRL adoption. In Malaysia, Regulator 3 and Regulator 4 were keen to know how XBRL could be implemented on a trial basis even though XBRL was still new in Malaysia. This is because Regulator 3 had intentions to better understand how XBRL could be implemented in order to reap the benefits of XBRL. Since XBRL adoption was limited to Regulator 1, Regulator 3 wanted to know how XBRL could be accepted by filers. Meanwhile, Regulator 4 also wanted to know how the pilot project could ensure XBRL readiness. Both Regulator 3 and Regulator 4 had adopted XBRL on a trial basis as they had sincere intentions to understand and adopt XBRL on a trial basis before the actual adoption. During this phase, regulators gathered ideas from the small-Regulator 3ale trials initiated by Regulator 1 since Regulator 1 was an early adopter. Regulator 1 had adopted XBRL after limited trials prior to deciding. The pilot test by Regulator 1 could influence other regulators (Regulator 3, Regulator 2 and Regulator 4) to decide whether to adopt the XBRL at the later phase.

In the case of this study, the trialability could be a challenge to regulators as each regulator faces limited adoption in the Malaysian context due to limited trials on XBRL by regulators. Comparatively, most past studies (Doolin \& Troshani, 2007; Cordery, et al., 2011; David, 2016) found that trialability was an important influential factor to XBRL adoption. This is because Cordery et al. (2011) agreed that trialability could reduce uncertainty during technology adoption. In relation to the current context among regulators in Malaysia, it is evident that the lack of trialability of XBRL among regulators could be a challenge to adopt when there is a challenge to the advantages of $\mathrm{XBRL}$. This is because each regulator was intent to see how XBRL suits the current environment in order to achieve the objectives of XBRL adoption.

\section{Summary and Conclusion}

This study aims in identifying and understanding factors related to the XBRL adoption process among the four regulators in Malaysia. This study found that the factors involved in each regulator differ based on the objectives of adopting XBRL. Based on this study, relative advantage and trialability are the driving factors during the knowledge 
gathering and persuasion stage. The findings were based on technological perspective, namely relative advantage and trialability at the knowledge and persuasion level. When deciding on the XBRL taxonomy, regulators need to understand the factors associated with certain elements of XBRL taxonomy such as the compatibility, stability and standardisation. At this phase, regulators need to understand and decide on the process that produces a stable XBRL instance document and standardises XBRL adoption. Additionally, factors related with the readiness to adopt XBRL are related to the stability required for producing XBRL instance documents and standardisation of XBRL submission. The implication of this finding is regulators need to understand the environment that involves filers. This is because regulators need to develop the XBRL taxonomy, submission template and platform that suits both regulators and filers. In addition, regulators must ensure that the XBRL taxonomy is compatible with the current environment, being stable and less complex.

This study is not without limitations. The study only involved four regulators that represented Malaysia in the case study. However, it might be difficult to generalise the findings of this study to other contexts since the Malaysian perspective might differ with other contexts. The research has shown a wide understanding of the adoption process among the four regulators, which provides a thorough understanding and highlights some issues that can be used by other government agencies, IT vendors, professional accounting bodies and practitioners when planning XBRL adoption.

Secondly, the research approach for this study is qualitative in nature. There has been a need to study and gain a thorough understanding of XBRL adoption as well as examine what can be incorporated into the adoption processes that could determine the existing adoption stages particularly, the knowledge gathering and persuasion phase. This study had conducted semi-structured interviews and document analysis in order to provide rich contextual data associated with organisational issues in Malaysia. However, this method could provide a tinge of bias among respondents comprising officers involved in XBRL development, from each regulator that will influence the findings of this study. Hence, data collection was not conducted using semi-structured interviews with other stakeholders who were directly or indirectly involved with XBRL adoption. Thus, this might cause the analysis and discussions of this case study to be highly contextual in nature and might potentially also lead to a degree of biasness. Hence, the response obtained from interviewees in this study cannot represent the views of other practitioners and filers regarding XBRL adoption among regulators.

This study has provided in-depth views from a regulator's perspective, which were based on previous studies. One contribution of this study was to validate the driving factors and challenges based on the analysis of the regulators who have played the role by the regulators to enhance XBRL adoption even though the timeline for the adoption process differed among them. The findings in this study serve as guidelines to other regulators in Malaysia and other countries that have plans to adopt XBRL.

\section{Acknowledgement}

We wish to thank the Universiti Tenaga Malaysia and Universiti Teknologi MARA for their support and funding.

\section{References}

Abdullah, A., Khadaroo, I., \& Shaikh, J. (2009). Institutionalisation of XBRL in the US and UK. International Journal Managerial and Financial Accounting, X(Y), 1-13. https://doi.org/10.1504/IJMFA.2009.025057

Abedin, M. T., \& Dawan, M. M. (2016). A Panel Data Analysis for Evaluating the Profitability of the Banking Sector in Bangladesh. Asian Journal of Economics and Empirical Research, 3(2), 163-171. https://doi.org/10.20448/journal.501/2016.3.2/501.2.163.171

Abiola, I., \& Olausi, A. S. (2014). The impact of credit risk management on the commercial banks performance in Nigeria. International Journal of Management and Sustainability, 3(5), 295-306.

Adusei, C. (2018). Determinants of Non-Performing Loans in the Banking Sector of Ghana Between 1998 and 2013. Asian Development Policy Review, 6(3), 142-154. https://doi.org/10.18488/journal.107.2018.63.142.154

Al-Jabri, I. M., \& Sohail, M. S. (2012). Mobile Banking Adoption: Application of Diffusion of Innovation Theory. Journal of Electronic Commerce Research, 13(4), 379-392.

Cheng, C. P., Phung, M. T., Hsiao, C. L., Shen, D. B., \& Chen, B. S. (2018). Impact of Operational Risk Toward the Efficiency of Banking-Evidence from Taiwans Banking Industry. Asian Economic and Financial Review, 8(6), 815-831. https://doi.org/10.18488/journal.aefr.2018.86.815.831

Chidoko, C., \& Mashavira, N. (2014). An analysis of corporate governance in the banking sector of Zimbabwe. Humanities and Social Sciences Letters, 2(3), 174-180. 
Cohn, M. (2017, July 28). XBRL makes progress globally. Retrieved from https://www.accountingtoday.com/news/xbrl-makes-progress-globally

Cordery, C. J., Fowler, C. J., \& Mustafa, K. (2011). A solution looking for a problem: factors associated with the non-adoption of XBRL. Pacific Accounting Review, 2(1), 69-88. https://doi.org/10.1108/01140581111130634

David, J. (2016). The non-adoption of XBRL by professional and government organisations in New Zealand and its implications for stakeholders. (Ph.D), Victoria University of Wellington. Retreived from http://researcharchive.vuw.ac.nz/xmlui/handle/10063/5459

Dedrick, J., \& West, J. (2003). Why Firms Adopt Open Source Platforms: A Grounded Theory of Innovation and Standards Adoption. Standard Making: A Critical Research Frontier for Infomation Systems MISQ Special Issue Workshop (pp. 236-258).

Depietro, R., Wiarda, E., \& Fleischer, M. (1990). The Context for Change: Organization, Technology and Environment. The processes of technological innovation (pp. 151-175). Lexington, Mass.: Lexington Books.

Doolin, B., \& Troshani, I. (2007). Organizational Adoption of XBRL. Electronic Markets, 17(3), 199-209. https://doi.org/10.1080/10196780701503195

Dunne, T., Helliar, C., Lymer, A., \& Mousa, R. (2013). Stakeholder engagemnet in internet financial reporting: The diffusion of XBRL in the UK. The British Accounting Review, 45, 167-182. https://doi.org/10.1016/j.bar.2013.06.012

Ekpete, M. S., \& Iwedi, M. (2017). Financial Intermediation Functions of Microfinance Banks in Nigeria: A Vector Autoregressive and Multivariate Approach. International Journal of Economics and Financial Modelling, 2(1), 7-24. https://doi.org/10.20448/811.2.1.7.24

Elkhayat, N., \& ElBannan, M. A. (2018). State Divestitures and Bank Performance: Empirical Evidence from the Middle East and North Africa Region. Asian Economic and Financial Review, 8(2), 145-171. https://doi.org/10.18488/journal.aefr.2018.82.145.171

Folorunso, O., Vincent, R. O., Adekoya, A. F., \& Ogunde, A. O. (2010). Diffusion of Innovation in Social Networking Sites among Universities Students. International Journal of Computer Science and Security, 4(3), 361-373. https://doi.org/10.5539/cis.v3n4p80

Ghani, E. K., Laswad, F., \& Tooley, S. (2009). Digital Reporting Formats: Users' Perceptions, Preferences and Performance. The International Journal of Digital Accounting Research, 9, 45-98. https://doi.org/10.4192/1577-8517-v9_3

Ghani, E., Laswad, F., \& Tooley, S. (2011). Functional fixation: Experimental evidence on the presentation of financial information through different digital formats. British Accounting Review, 43(3), 186-199. https://doi.org/10.1016/j.bar.2011.06.004

Ghosh, P. K., Khatun, M., \& Tarafdar, P. (2018). Bankruptcy Via Earning Volatility: Does it Integrate in Financial Institutions? Asian Economic and Financial Review, 8(1), 52-62. https://doi.org/10.18488/journal.aefr.2018.81.52.62

Hallunovi, A., \& Berdo, M. (2018). The Relationship between Risk Management and Profitability of Commercial Banks in Albania. Asian Themes in Social Sciences Research, 1(2), 44-49. https://doi.org/10.33094/journal.139.2018.12.44.49

Henderson, D., Sheetz, S. D., \& Trinkle, B. S. (2012). The determinants of inter-organizational and internal in-house adoption of XBRL: A structural equation model. International Journal of Accounting Information Systems, 13, 109-140. https://doi.org/10.1016/j.accinf.2012.02.001

Hussin, H., \& Noor, R. M. (2005). Innovating Business Through E-Commerce: Exploring the willingness of Malaysian SMEs. The Second International Conference on Innovation in IT (IIT'05) (pp.1-10).

Iacovou, C. L., Benbasat, I., \& Dexter, A. S. (1995). Electronic Data Interchange and Small Organizations: Adoption and Impact of Technology. Management Information Systems Research Center, University of Minnesota, 19(4), 465-485. https://doi.org/10.2307/249629

Krishnan, A. T. B., \& Kumaran, A. (2015). Future Forward: Banking on Youngsters to Create Value. International $\begin{array}{llll}\text { Journal of Management and } & \text { Sustainability, } & 4(8), & \text { 173-182. }\end{array}$ https://doi.org/10.18488/journal.11/2015.4.8/11.8.173.182 
Liu, X., \& Yin, Z. (2018). A Warning Model of Centralized Credit Default in Commercial Banks. International Journal of Emerging Trends in Social Sciences, 2(1), 17-20. https://doi.org/10.20448/2001.21.17.20

Moore, G. C., \& Benbasat, I. (1991). Development of an instrument to measure the perceptions of adopting an information technology innovation. Information Systems Research, 2(3), 192-222. https://doi.org/10.1287/isre.2.3.192

Mousa, R. (2010). E-Government Adoption Process: XBRL Adoption in HM Revenue and Customs and Companies House. Ph.D, University of Birmingham. Retrieved from https://etheses.bham.ac.uk/id/eprint/1752/

Nazal, A. I. (2017). Added Value of Ijarah Tamwilia Service in Jordanian Islamic Bank (Case Study of Contract No: 2012/500). Humanities and Social Sciences Letters, 5(1), 11-17. https://doi.org/10.18488/journal.73/2017.5.1/73.1.11.17

Omodero, C. O., \& Ogbonnaya, A. K. (2018). Corporate Tax and Profitability of Deposit Money Banks in Nigeria. Journal of Accounting, Business and Finance Research, 3(2), 47-55. https://doi.org/10.20448/2002.32.47.55

Ong, J. W., Poong, Y.-S., \& Ng, T. H. (2008). 3G Services Adoption among University Students: Diffusion of Innovation Theory. Communiction of the IBIMA, 3, 114-121.

Pinsker, R., \& Li, S. (2008). Costs and Benefits of XBRL Adoption: Early Evidence. Communication of the ACM, 51(3), 47-50. https://doi.org/10.1145/1325555.1325565

Rodgers, J. A., Yen, D. C., \& Chou, D. C. (2002). Developing e-business: a strategic approach. Information Management \& Computer Security, 10(4), 184-192. https://doi.org/10.1108/09685220210436985

Rogers, E. M. (1983). Diffusion of Innovations (3rd ed.). New York: Free Press.

Rogers, E. M. (2003). Diffusion of Innovations (5th ed.). New York: Free Press.

Rosa, F. L., \& Caserio, C. (2013). Are Auditors Interested in XBRL? A Qualitative Survey of Big Auditing Firms in Italy, pp. 13-45. https://doi.org/10.1007/978-3-642-35761-9_2

Slyke, C. V., Belanger, F., \& Comunale, C. L. (2004). Factors influencing the adoption of web-based shopping: the impact of trust. ACM SIGMIS Database: the DATABASE for Advances in Information Systems, 35(2), 32-49. https://doi.org/10.1145/1007965.1007969

Steenkamp, L., \& Nel, G. (2012). The Adoption of XBRL in South Africa: an emrerical study. The Electronic Library, 30(3), 409-425. https://doi.org/10.1108/02640471211241672

Syadullah, M. (2018). ASEAN Banking Efficiency Review Facing Financial Services Liberalization: The Indonesian Perspective. Asian Development Policy Review, 6(2), 88-99. https://doi.org/10.18488/journal.107.2018.62.88.99

Taylor, E. Z., \& Dzuranin, A. C. (2010). Interactive Financial Reporting: An Introduction to eXtensible Business Reporting Language (XBRL). Issues in Accounting Education, 25(1), 71-83. https://doi.org/10.2308/iace.2010.25.1.71

Troshani, I., \& Doolin, B. (2005). Drivers and Inhibitors Impacting Technology Adoption: A qualitative Investigation into the Australian Experience with XBRL. Proceedings of 18th Bled eConference eIntegration in Action (pp. 1-16). Bled, Slovenia https://doi.org/10.4018/jebr.2007100106

Troshani, I., \& Rao, S. (2007). Drivers and Inhibitors to XBRL Adoption: A Qualitative Approach to Build a Theory in Under-Researched Areas. International Journal of E-Business Research, 3(4), 98-111.

Valmohammadi, C., \& Dashti, S. (2016). Using interpretive structural modeling and fuzzy analytical process to identify and prioritize the interactive barriers of e-commerce implementation. Information \& Management, 53, 157-168. https://doi.org/10.1016/j.im.2015.09.006

Zhu, K., Kraemer, K., \& Xu, S. (2003). Electronic business adoption by Europian firms: a cross-country assessment of the facilitators and inhibitors. Europian Journal of Information Systemss, 12, 251-268. 